\title{
APRESENTAÇÃO: \\ O PAPEL DA PRAGMÁTICA NA VISÃO DE KANAVILLIL RAJAGOPALAN
}

\section{THE ROLE OF PRAGMATICS IN KANAVILLIL RAJAGOPALAN'S VIEW}

\author{
Camilla Santero Pontes 1 \\ Universidade Federal da Bahia \\ Cecilia Aguirre² \\ Universidade Federal da Bahia
}

Dentre os linguistas brasileiros que contribuíram para o desenvolvimento da Pragmática no Brasil destaca-se o professor Kanavillil Rajagopalan. Professor Titular na área de Semântica e Pragmática das Línguas Naturais da Universidade Estadual de Campinas (UNICAMP), Rajagopalan inaugurou, junto com Rodolfo Ilari³, o debate no âmbito da Linguística sobre os limites do significado entre Semântica e Pragmática e sobre a validade de

\footnotetext{
1 Endereço eletrônico: camillasantero_6@hotmail.com.

2 Endereço eletrônico: cga.ufba.2015@gmail.com.

3 O debate, constituído por uma série de três artigos, foi publicado no Cadernos de Estudos Linguísticos e Literários número 13, UNICAMP, 1987. Disponível em: $<$ https://periodicos.sbu.unicamp.br/ojs/index.php/cel/issue/view/421>.
} 
argumentos interpretativos - os elementos extralinguísticos como o falante, suas intenções comunicativas, o contexto - contribuindo desta forma com a discussão sobre o próprio objeto de estudo da Linguística e para a constituição da Pragmática como área de estudo na academia brasileira. Colocamos de relevo aqui algumas de suas contribuições, pois inspiraram a realização deste dossiê.

Em um número especial da Revista D.E.L.T.A publicado em 1999, Rajagopalan apresenta o artigo Os caminhos da Pragmática no Brasil, onde ressalta a atenção que pesquisadores brasileiros tem dado ao desenvolvimento da área mundo afora e, ao mesmo tempo, assinala a grande dificuldade de fazer um mapeamento dessas pesquisas na academia brasileira. Entre os fatores que condicionam esse mapeamento, o autor menciona em primeiro lugar, a própria indefinição da Pragmática, o que atinge pesquisadores tanto brasileiros como do mundo todo; em segundo lugar, a falta de consenso sobre como e quando a Pragmática surgiu como área de investigação; e, em terceiro lugar, e mais importante para ele, a falta de identificação explícita dos estudos dedicados à área.

Essa falta de identificação se deve, segundo Rajagopalan (1999, p. 325) às grandes divergências existentes entre os pesquisadores, quanto a proximidade com outras teorias e as relações hierárquicas que delimitam as subáreas dentro da Linguística. Para elucidar essa questão, cita os embates de diversos cientistas na tentativa de discernir a diferença fundamental entre Pragmática e Análise do Discurso, demarcar os campos de estudo entre Semântica e Pragmática, estabelecer o lugar da Pragmática no confronto entre Formalismo e Funcionalismo, e analisar a dicotomia entre "a Gramática da forma e a Pragmática do uso" (Rajagopalan, 1999, p. 329).

Porém, afirma que para além desses embates teóricos às vezes irreconciliáveis há um grupo de pesquisadores que defendem uma relação de 
complementaridade, "pacífica e harmoniosa" (1999, p. 331) entre abordagens diferentes. Nesse sentido, Rajagopalan valoriza a convivência harmônica de diferentes posturas, prefere "celebrar a anarquia saudável" que reina no campo da Pragmática (Rajagopalan, 1996, p. 06).

Da mesma forma, defende o trabalho com "dados recolhidos da vida realmente vivida pelos usuários de língua e não inventados pela imaginação fértil dos pesquisadores" (Rajagopalan, 1999, p. 332) e observa que a preocupação de analisar dados autênticos e de contemplar unidades maiores que a sentença une estudiosos de diversas áreas, por exemplo, da Análise do Discurso, Análise Conversacional, Linguística do Texto, Sociolinguística, entre outras.

Ampliando ainda mais o escopo, Rajagopalan aponta para a afinidade existente entre Pragmática e Linguística Aplicada: “é de se esperar que os pesquisadores que se interessam pela Pragmática também se interessem pelas questões que são tratadas sob o rótulo de 'Linguística Aplicada'” (Rajagopalan, 1999, p.332. Aspas do autor). Concorda com Mey (1993, p.286 apud Rajagopalan, 1999, p.332) que a Pragmática deve ficar cada vez mais voltada para questões de interesse social, de forma a aproximar as duas vertentes da Linguística - como ciência teórica pura e como ciência aplicada aos usos da linguagem. Concorda também com o pensamento de Pennycook para quem "como linguistas aplicados estamos envolvidos com linguagem e educação, uma confluência de dois dos aspectos mais essencialmente políticos da vida" (Pennycook, 1998, p. 24, apud Rajagopalan, 1999, p. 333).

No capítulo Repensar o papel da LA, publicado no livro Por uma Linguística Aplicada InDisciplinar de Moita Lopes (2006), Rajagopalan retoma e aprofunda essa discussão sobre o papel da Linguística e da Linguística Aplicada, revisitando linguistas e teorias linguísticas para avaliar a vertente ortodoxa da Linguística sob uma nova luz. Rejeita a Linguística cujas discussões 
se fundamentam no princípio neopositivista da neutralidade do cientista, para quem os objetivos observacionais e descritivos estão dissociados do uso e dos usuários e, o contexto social, relegado a um segundo plano. Pelo contrário, Rajagopalan defende uma Linguística crítica e intervencionista, que procura influenciar a forma em que a realidade se apresenta, em outras palavras, intervir de forma consequente nos problemas linguísticos constatados, teorizando a linguagem de forma mais adequada a esses problemas. Para o pesquisador, é preciso tomar consciência de que para a teoria ter de fato utilidade deve ser concebida em primeiro lugar levando em conta possíveis fins práticos. No que diz respeito à Linguística Aplicada, para o pesquisador cabe a difícil tarefa de "ressuscitar" a enfraquecida Linguística ao repensar o próprio lugar da teoria, chegando dessa maneira, talvez, a absorver boa parte da reflexão teórica em Linguística.

No que se refere à Pragmática, para Kanavillil Rajagopalan “o que há é a pragmática, sendo pragmática, a semântica e a sintaxe produtos da atividade intelectual que consiste em progressiva abstração" (RAJAGOPALAN, 1987, pg. 91); “o interesse da pragmática [...] sempre foi a inexistência da disciplina propriamente dita - na verdade, parece muito mais sensato falar em pragmáticas, no plural" (Rajagopalan 1996, p. 06); “A grande variedade de assuntos tratados é a prova de que a pragmática mantém vínculos com muitas outras disciplinas e demais subáreas dentro da linguística" (Rajagopalan 1999, p. 332) e por último, "os possíveis pontos de encontro entre a pragmática e a linguística aplicada, ambas definidas em termos amplos, foram sinalizados nas [...] palavras de Mey (1993:286), que pede que a pragmática fique cada vez mais voltada às questões de interesse social" (Rajagopalan 1999, p. 332); “tentativas [...] de interrogar a linguística teórica, procurando torná-la eticamente responsável e consciente das suas implicações ideológicas estão abrindo novos caminhos para os pesquisadores em pragmática"(Rajagopalan 1999, p. 332). 
Desta forma, a Pragmática, na visão do pesquisador, ocuparia um lugar de transição, de articulação, tendo, no centro, como ponto de partida, o contexto ou situação social concreta, onde surgem problemas concretos a partir do uso da língua em sociedade, problemas linguísticos que podem vir a interferir na vida das pessoas. Esses problemas seriam abordados pela Pragmática, a partir das suas diferentes perspectivas e interseções disciplinares, dando início ao estudo da materialidade da língua em contexto de uso, sendo a Pragmática o nível mais empírico, a partir do qual se avança na análise em progressivos graus de abstração.

Para Rajagopalan, a interseção da Pragmática com diversas teorias linguísticas assim como com as próprias subáreas da Linguística dificulta sua definição, bem como sua visibilidade. No entanto, aponta para a Pragmática como a subárea que mais contribui com a revalorização da Linguística, pois permite a aproximação da teoria com a prática social concreta, da forma linguística com seu uso em contextos específicos, partindo do conhecimento e crenças dos próprios usuários da língua para abordar problemas concretos. Dessa forma, para o pesquisador, o papel da Pragmática é abrir o caminho na Linguística para uma teorização ética, responsável e consciente de suas implicações ideológicas, encontrando-se com a Linguística Aplicada nesse interesse comum.

No que diz respeito a este volume, dos sete trabalhos aqui apresentados, seis deles mencionam explicitamente a Pragmática no título, como os artigos sobre as funções semântico-pragmáticas da partícula discursiva y e sobre a função pragmática dos diminutivos; também no caso da variação pragmática, Pragmática e cognição, ou na discussão de temas específicos como a cortesia linguística e a competência intercultural pragmática.

Nesse sentido, em uma rápida consulta ao Catálogo de Teses e Dissertações da CAPES, uma amostra de 98 teses na grande área da Linguística, 
Letras e Artes revelou que aproximadamente 30\% delas se insere na área Pragmática. Dessa porcentagem, aproximadamente 50\% mencionam a Pragmática explicitamente no título, e os outros 50\% mencionam teorias e temas específicos do campo da Pragmática como cortesia/polidez ou descortesia/impolidez, o princípio de cooperação, a teoria da relevância, inferência, dêixis e metáfora, atos de fala, pedidos, recusas e convites. Embora não possa ser considerado conclusivo, esse resultado revela, entre outras coisas, a necessidade de dar maior impulso e visibilidade aos estudos na área da Pragmática na academia brasileira.

Para além de avivar os estudos nessa área, os trabalhos que compõem este dossiê são representativos de uma "anarquia saudável”, nas palavras de Rajagopalan: eles refletem sua confluência com subáreas da Linguística, como a Morfologia e a Sintaxe, abordam aspectos sociolinguísticos como a variação pragmática, discorrem sobre aspectos sociopragmáticos da cortesia e descortesia e tocam em questões que dizem respeito à aprendizagem de espanhol por falantes de português, como o processo inferencial na aprendizagem e a competência intercultural pragmática. De forma ampla, eles se inserem na perspectiva de uma pragmática socialmente sensível, pois procuram descrever, explicar e entender diversos fenômenos que se observam em contextos específicos, como a sala de aula e outras situações sociais concretas.

Abrindo o volume, Natália dos Santos Figueiredo da Universidade Federal da Integração Latino-americana (UNILA) apresenta o texto Variação pragmática de atos de fala diretivos do espanhol na tríplice fronteira: Argentina, Brasil e Paraguai. O estudo foi realizado com o intuito de descrever o ato de fala diretivo do pedido em quatro variedades do espanhol: de Assunção, Buenos Aires, e de duas cidades fronteiriças, Ciudad del Este, no Paraguai e Puerto Iguazú, na Argentina. A autora compara as estratégias de 
cortesia utilizadas por interagentes dessas quatro localidades com base na descrição da variação pragmática, fundamentando suas observações em Márquez-Reiter (2002). Considerando a ecologia das línguas em uma região de intenso contato linguístico-cultural, a autora se pergunta qual a identidade de fronteira que finalmente prevalece. A análise das estratégias de cortesia utilizadas pelos interagentes na realização do ato de fala do pedido compreende estratégias de atenuação e intensificação e o grau de direticidade ou indireticidade. Esse trabalho contribui com a descrição do contato linguístico no território de fronteira, sob um viés pragmático, muito pouco explorado pelos pesquisadores.

Dando continuidade ao volume, Adriana Marcelle Andrade e Cleiton Pontes Pereira, da Universidade Federal do Rio Grande do Norte (UFRN), apresentam o manuscrito La cortesía lingüística en la conversación coloquial: los marcadores ¿né? Y ¿cachái? En la gestión de las imágenes sociales. Os autores partem da necessidade da gestão de imagem que envolve toda interação comunicativa. Esta se realiza mediante estratégias corteses que variam segundo a comunidade de fala, os princípios que regem a interação comunicativa e o comportamento discursivo particular de cada cultura. Assim, tomam como corpus de análise diálogos entre jovens universitários das cidades de Natal e Santiago do Chile para comparar os usos dos marcadores discursivos né? e ¿cachai? na perspectiva da Pragmática Sociocultural, valendo-se dos conceitos de autonomia e filiação de Diana Bravo $(1999,2004)$ e Fant e Granato (2002). Os resultados deste estudo nascem da análise da função pragmática desses marcadores, que se revelam estratégias de cortesia com valores diferentes, levando em consideração os aspectos linguístico e sociocultural assim como a necessidade de imagem das comunidades de fala selecionadas.

O texto Entre bolhas e grietas: a polarização político-ideológica nas redes sociais insere-se também dentro do campo da Pragmática Sociocultural. 
O autor, Fábio Barbosa de Lima da Universidade de São Paulo (FATEC), analisa os fenômenos de bolha e grieta nas interações de conteúdo ideológico publicadas na rede social Facebook, no Brasil e na Argentina. Segundo o autor, esse fenômeno de polarização se observa cotidianamente no enfrentamento direto, na intolerância, na negação da opinião do outro e na constituição de comunidades ideologicamente posicionadas, no entanto, as redes sociais dão uma nova configuração a esse enfrentamento, amplificando sua dimensão e alcance. Por esse motivo, ele toma como lócus de pesquisa o Facebook: as redes sociais têm se tornado um campo importante para os estudos da interação humana e as formas de se comunicar, uma vez que pela ausência da interação face a face os interagentes podem ora fazer um uso exagerado da cortesia, ora manifestar comportamentos próximos à descortesia.

Elena Godoy e Crisbelli Domingos, da Universidade Federal do Paraná (UFPR) apresentam o texto $\mathbf{O}$ desenvolvimento da competência intercultural pragmática e os estereótipos no ensino de ELE. As autoras objetivam demonstrar que o desenvolvimento de uma competência intercultural pragmática e os estereótipos no ensino de ELE são mais amplamente compreendidos quando observados a partir do conceito de atração cultural. Fundamentam o estudo a partir da teoria de Sperber (2012) e Claidière, ScottPhillips e Sperber (2014), que visa a descrição causal e natural dos fenômenos culturais. Para as autoras, o ensino de língua adicional oferece um campo fértil para essa descrição, uma vez que pressupõe uma abordagem intercultural para a aquisição das experiências e aptidões interacionais requeridas em uma sociedade pluricultural e multilíngue. Para isto, advertem, é preciso que o estudante, a partir da sua própria estrutura cognitiva, possa sistematizar outras identificando, interpretando e intuindo as diferenças e semelhanças. Com base nestas considerações, as autoras apresentam o conceito de atração cultural a partir de teorias que dialogam com a Pragmática Cognitiva e descrevem como 
essa concepção pode iluminar o desenvolvimento da competência pragmática do estudante através do manejo de diferenças e choques culturais.

O texto Pragmática e cognição ou o processo inferencial de brasileiros na aprendizagem da língua espanhola escrito por Sebastião Lourenço da Universidade Estadual de Ponta Grossa (UEPG) tem como objetivo descrever como ocorrem os processos inferenciais dos estudantes brasileiros na aprendizagem do artigo masculino singular el e do artigo neutro lodo espanhol. Com base na Teoria da Relevância de Sperber e Wilson (2001) o autor analisa treze produções textuais em língua espanhola a partir do questionamento sobre qual ou quais regras inferenciais atuam no processo de aprendizagem. O estudo do aspecto inferencial da aprendizagem diferencia este trabalho de outros prévios, uma vez que abordam o mesmo tema a partir da análise contrastiva de aspectos morfossintáticos.

O artigo Funciones semántico-pragmáticas de la partícula discursiva "y" en las narraciones orales de estudiantes brasileños de ELE, de Antônio Messias Nogueira da Universidade Federal da Bahia (UFBA), analisa as funções da partícula discursiva y em narrações orais de estudantes brasileiros de espanhol. O estudo se fundamenta na perspectiva da Pragmagramática, oriunda da Gramática Funcional, definida principalmente como uma sintaxe interdisciplinar. O autor é consciente do desafio que esta abordagem enseja, não só porque analisa essa partícula na interlíngua dos estudantes a partir de um corpus de narrativas orais, mas também por se tratar de uma partícula de natureza variada e de difícil sistematização. Porém, segundo o autor, não deve ser considerada por isso irrelevante para a interpretação dos discursos que o estudante de língua estrangeira produz, uma vez que o discernimento do seu valor semântico-pragmático é imprescindível para a compreensão e produção do gênero textual selecionado. Essa pesquisa toma como base trabalhos anteriores desenvolvidos por Escandell Vidal (1996), Domínguez García (2007, 
2010), PorrocheBallesteros (1993), Briz (1998), Halliday y Hasan (1976), entre otros.

Encerrando este dossiê, Camilla Guimarães Santero Pontes, da Universidade Federal da Bahia (UFBA), apresenta o artigo A função pragmática dos diminutivos em corpora orais das variedades madrilena e carioca. Trata-se de um trabalho descritivo-comparativo que tem como objetivo identificar as funções morfopragmáticas dos diminutivos; especificamente, o estudo objetiva observar se as formações diminutivas estão a serviço da construção de face do entrevistado. O corpus está constituído pela atividade entrevista sociolinguística, contrastando os usos dos diminutivos na variedade carioca do português e na variedade madrilena do espanhol. A autora toma como base de análise a Morfopragmática de Dressler e Merlini Barbaresi (2020) e a Teoria de elaboração de faces de Goffman (1980). O caráter inovador desse trabalho reside no fato de que rompe com a abordagem tradicional dos diminutivos a partir da Morfologia e da Semântica. Assim, propõe analisar o valor pragmático dos diminutivos, que tanto em português quanto em espanhol, podem vir a revelar um valor atenuante, assim como serem associados a outras conotações - afetivas, irônicas etc - para além do seu valor semântico de dimensão.

Concluindo, percebe-se a qualidade e a variedade de perspectivas nesses trabalhos, o que reflete a convivência harmônica entre diferentes posturas teóricas, atingindo nosso principal objetivo: contribuir para a visibilidade e o desenvolvimento da Pragmática na academia brasileira.

Desejamos uma boa leitura.

13 de fevereiro de 2021

Camilla Santero Pontes (UFBA/UnB)

Cecilia Aguirre (UFBA) 


\section{REFERÊNCIAS}

MEY, Jacob. Pragmatics. Oxford: Blackwell, 1993.

PENNYCOOK, Alistair. (1998) A linguística aplicada dos anos 90: em defesa de uma abordagem crítica. In: I. SIGNORINI \& M. C. CAVALCANTI (orgs.) Linguística Aplicada e Transdisciplinaridade. Campinas: Mercado de Letras: 23-50.

RAJAGOPALAN, Kanavillil. Repensar o papel da LA. In: Lopes, Moita (org). Por uma LA Indisciplinar, 2006 (p. 149-168)

RAJAGOPALAN, Kanavillil. Os caminhos da Pragmática no Brasil. D.E.L.T.A., Vol. 15, N. $\quad$ ESPECIAL, $1999 \quad$ (p. 323-338). Disponível em https://www.scielo.br/scielo.php?script=sci_arttext\&pid=S0102-44501999000300013

RAJAGOPALAN, Kanavillil. Apresentação. Caderno de Estudos Linguísticos v. 30 (1996): Pragmática. Disponível em https://periodicos.sbu.unicamp.br/ojs/index.php/cel/issue/view/444

RAJAGOPALAN, K. Quando '2+3' não é igual a '3+2': A semântica e a pragmática das construções simétricas em língua natural. Cadernos de Estudos Linguísticos, Número 13, 1987, pg. 67-96. Disponível em https://periodicos.sbu.unicamp.br/ojs/index.php/cel/issue/view/421 